\title{
A Model System to Explore the Detection Limits of Antibody-Based Immuno-SPECT Imaging of Exclusively Intranuclear Epitopes
}

Mathew Veal ${ }^{1}$, Gemma Dias ${ }^{1}$, Veerle Kersemans ${ }^{1}$, Deborah Sneddon ${ }^{1,2}$, Stephen Faulkner ${ }^{2}$, and Bart Cornelissen ${ }^{*}$

${ }^{1}$ Medical Research Council Oxford Institute for Radiation Oncology, Department of Oncology, University of Oxford, UK

${ }^{2}$ Department of Chemistry, University of Oxford, UK

Word count: 5,554

Running title: Limits of IgG-TAT imaging

Key words: Molecular imaging, nuclear targeting, PET, SPECT, cell penetrating peptide, TAT

Competing financial interests. The authors have no financial conflicts of interest to declare.

\section{* To whom correspondence should be addressed:}

Professor Bart Cornelissen, PhD

University of Oxford

MRC Oxford Institute for Radiation Oncology, Department of Oncology

Old Road Campus Research Building

Off Roosevelt Drive

Oxford OX3 7LJ

UK

bart.cornelissen@oncology.ox.ac.uk

$1^{\text {st }}$ author in training:

Mathew Veal

University of Oxford

MRC Oxford Institute for Radiation Oncology, Department of Oncology

Old Road Campus Research Building

Off Roosevelt Drive

Oxford OX3 7LJ

UK

mathew.veal@oncology.ox.ac.uk

Immediate Open Access: Creative Commons Attribution 4.0 International License (CC BY) allows users to share and adapt with attribution, excluding materials credited to previous publications. License: https://creativecommons.org/licenses/by/4.0/. Details: https://jnm.snmjournals.org/page/permissions. 


\section{ABSTRACT}

PURPOSE: Imaging of intranuclear epitopes using antibodies tagged to cell penetrating peptides (CPPs) has great potential given its versatility, specificity and sensitivity. However, this process is technically challenging because of the location of the target. Previous research has demonstrated a variety of intranuclear epitopes that can be targeted with antibody-based radioimmunoconjugates (RICs). Here, we developed a controlled expression model of nuclear localised GFP to interrogate the technical limitations of intranuclear SPECT using RICs, notably the lower target abundance detection threshold.

METHODS: We stably transfected the lung adenocarcinoma cell line H1299 with an EGFPtagged histone (H2B-EGFP) and generated four cell lines expressing increasing levels of GFP (EGFP). EGFP levels were quantified using western blot, flow cytometry, and ELISA. An antiGFP antibody (GFP-G1) was modified using $\mathrm{DBCO}-\mathrm{N}_{3}$ based strain-promoted azide-alkyne cycloaddition (SPAAC) with the CPP TAT (GRKKRRQRRRPPQGYG-hA(N $\left.\mathrm{N}_{3}\right)$ ), which also includes a nuclear localisation sequence, and the metal ion chelator $\mathrm{N}_{3}-\mathrm{Bn}-\mathrm{DTPA}$ to allow radiolabelling with ${ }^{111} \mathrm{In}$. Cell uptake of $\left[{ }^{111} \mathrm{In}\right] \mathrm{In}-\mathrm{GFP}-\mathrm{G} 1-\mathrm{TAT}$ was evaluated across five cell clones expressing different levels of H2B-EGFP in vitro. Tumor uptake in xenograft-bearing mice was quantified to determine the smallest amount of target epitope that could be detected using $\left[{ }^{111} \mathrm{In}\right] \mathrm{In}-\mathrm{GFP}-\mathrm{G} 1-\mathrm{TAT}$.

RESULTS: We generated four H1299 cell clones expressing different levels of H2B-EGFP (0 1 Mcopies/cell, including WT H1299 cells). GFP-G1 monoclonal antibody was produced and purified in house and selective binding to H2B-EGFP was confirmed. The affinity $\left(\mathrm{K}_{\mathrm{D}}\right)$ of GFPG1 was determined as $9.1 \pm 3.0 \mathrm{nM}$. GFP-G1 was conjugated to TAT and DTPA. $\left[{ }^{111} \mathrm{In}\right] \mathrm{In}-\mathrm{GFP}-$ G1-TAT uptake in H2B-EGFP expressing cell clones correlated linearly with H2B-EGFP 
expression $(P<0.001)$. In vivo xenograft studies demonstrated that $\left[{ }^{111} \mathrm{In}\right] \mathrm{In}-\mathrm{GFP}-\mathrm{G} 1-\mathrm{TAT}$ uptake in tumor tissue correlated linearly with expression of H2B-EGFP $(P=0.004)$ and suggested a lower target abundance detection threshold of approximately 240,000 copies per cell.

CONCLUSIONS: Here, we present a proof of concept demonstration that antibody-based imaging of intranuclear targets is capable of both detecting the presence of an epitope of interest with a copy number above 240,000 copies per cell and is capable of determining differences in expression level above this threshold. 


\section{INTRODUCTION}

Molecular imaging enables non-invasive characterisation of biochemical features at a molecular level, performed on anything from a living cell to an entire organism (1). In parallel with other branches of personalised precision medicine, molecular imaging has become a rapidly expanding field of research, providing applications including early diagnostic tools, patient stratification, therapy guidance and post therapy evaluation. Nuclear imaging by positron emission tomography (PET) or single photon emission computerised tomography (SPECT) using radiolabelled modified antibodies, or radioimmunoconjugates (RICs), has already shown great promise in cancer imaging, owing to the specificity, versatility and dependable pharmacokinetics unique to monoclonal antibodies (2). Whilst the vast majority of research has focused on the development of monoclonal antibodies targeting extracellular epitopes on either cancer cell membranes, the extracellular matrix, or epitopes shed into the interstitial space, approximately $30 \%$ of cellular proteins are localised within the nucleus, orchestrating a myriad of physiologically and pathologically relevant processes (3). The opportunity to successfully target intranuclear epitopes would significantly expand the potential applications of molecular imaging.

Without modification, antibodies are unable to cross cellular membranes due to their size $(\sim 150,000 \mathrm{Da})$ and hydrophilicity. However, these barriers can be overcome using cell penetrating peptides (CPPs) (4). Cell penetrating peptides are short length peptides (less than 30 residues), that have the capacity to translocate across cellular membranes (5). Since the initial discovery of the membrane transduction capacities of the HIV-derived TAT peptide and drosophila antennapedia homeodomain protein-derived peptide (6-8), over 1,800 CPPs have been described (9). In addition, many CPPs have been experimentally validated in vitro and in vivo to facilitate the translocation 
of bioactive molecular cargoes of various sizes, up to $540,000 \mathrm{kDa}$, across cellular membranes with limited toxicity (10).

Apart from serving as a CPP, the TAT-peptide also contains a non-canonical nuclear localisation sequence (NLS), enabling nuclear translocation of its cargo. Previous research from our group and others has demonstrated that TAT-peptide-conjugated antibodies (IgG-TAT), can be used to image several intranuclear targets, including p21 (11), p27 (12), and the phosphorylated histone protein H2AX using both PET and SPECT (13-17). This proof of concept work has provided a tantalising glimpse into the potential of IgG-TAT -based PET/SPECT imaging of intranuclear targets.

Given the unparalleled adaptability of antibodies, the range of possible imaging applications using intranuclear IgG-TAT imaging probes is substantial. However, as with all imaging modalities, fundamental limitations in sensitivity are to be expected. Therefore, determining the minimum target epitope copy number required for antibody-based PET/SPECT imaging would be highly beneficial when novel protein markers are considered as potential targets. In vivo imaging using antibody fragments has been demonstrated with extracellular epitopes with copy numbers as low as 25,000 and 8,000 copies/cell $(18,19)$. Intracellular epitope detection limits would be expected to be significantly higher, but a quantitative description of this limit has not yet been explored.

To determine the lower threshold of target abundance required for successful intranuclear imaging using RICs, we developed a model system expressing different levels of a well-characterised, stably expressed, nuclear localised target protein construct, histone 2B tagged enhanced green fluorescent protein (H2B-EGFP). This strategy removes several experimental factors that could undesirably alter target abundance, such as the potential for the probe to influence target functionality and the innate variability and temporal changeability in dosages and responses where 
imaging target epitopes are induced by exogenous treatment. Removing these factors allowed for a more rigorous evaluation of the technical capabilities of antibody-based intranuclear imaging. 


\section{MATERIALS AND METHODS}

\section{Cell culture}

Human lung adenocarcinoma H1299 cells (ATCC) were cultured in Dulbecco's Modified Eagles Medium DMEM (Sigma), supplemented with 10\% foetal bovine serum (Life Technologies), 2 $\mathrm{mM}$ L-glutamine, 100 units $/ \mathrm{mL}$ penicillin, and $0.1 \mathrm{mg} / \mathrm{mL}$ streptomycin and maintained in a $5 \%$ $\mathrm{CO}_{2}$ humidified atmosphere at $37^{\circ} \mathrm{C}$. Cells were tested and authenticated by the providers. The cumulative length of culture was less than 6 months following retrieval from liquid nitrogen storage. Cells were tested for the absence of mycoplasma at regular intervals. Cells stably transfected with H2B-EGFP plasmid were cultured with $50 \mu \mathrm{g} / \mathrm{mL} \mathrm{G} 418 /$ geneticin to promote stability of transfection. Cells were harvested and passaged as required using trypsin-EDTA solution.

\section{Stable cell transfection and selection}

H1299 cells were seeded onto 6 well plate cell culture dishes and allowed to attach overnight to reach $75-90 \%$ confluency. Cells were then transfected with H2B-GFP plasmid (Addgene \#11680) (20) using lipofectamine 3000 (Invitrogen) according to manufacturer protocols. After transfection (48 h), stably transfected cells were selected by culture with $800 \mu \mathrm{g} / \mathrm{mL} \mathrm{G} 418$ antibiotic for several passages. Cells that survived initial selection were sorted for EGFP green fluorescence and plated as individual cells using flow assisted cell sorting (FACSAria III, BD Biosciences) (Supplementary Fig 1A). Individual cell colonies were expanded under G418 selection (200 $\mu \mathrm{g} / \mathrm{mL}$ ) and H2B-EGFP expression in candidate cell lines was initially assessed qualitatively using immunofluorescence microscopy. After establishing four stably transfected cell lines, in addition to untransfected H1299 cells, which were used as a negative control, H2B-EGFP expression was 
evaluated by western blot, immunofluorescence microscopy, flow cytometry and ELISA. Stability of H2B-EGFP expression in the absence of G418 was determined using flow cytometry (Supplementary Figure 1B).

\section{Production and purification of GFP-G1 monoclonal antibody}

The GFP-G1 mouse monoclonal antibody and associated hybridoma cell line was obtained from the Developmental Studies Hybridoma Bank (DSHB, University of Iowa; as deposited by Sanes, J.R. and Yamagata, M.) (21). Hybridoma cells were initially cultured from frozen stocks in RPMI medium supplemented with 10\% foetal bovine serum (Life Technologies), $2 \mathrm{mM}$ L-glutamine, 100 units $/ \mathrm{mL}$ penicillin, and $0.1 \mathrm{mg} / \mathrm{mL}$ streptomycin in a $5 \% \mathrm{CO}_{2}$ humidified atmosphere at $37^{\circ} \mathrm{C}$. Once they displayed exponential growth rates, hybridoma cells were maintained in CD Hybridoma medium (Thermo Fisher Scientific, MA, USA) before harvesting 14 days after the final passage. Supernatant enriched with GFP-G1 antibody was clarified by centrifugation (1400 x g, $10 \mathrm{~min}$ ) and filtered through a $0.2 \mu \mathrm{m}$ filter using a peristaltic pump before FPLC purification using a HiTrap Protein G HP antibody purification column (Cytiva, MA, USA). Purified antibody was buffer exchanged to PBS solution and stored at $-20^{\circ} \mathrm{C}$. Characterisation of antibody specificity and affinity $\left(\mathrm{K}_{\mathrm{D}}\right)$ was conducted using immunofluorescence microscopy and flow cytometry.

\section{Bioconjugation and radiolabelling}

Bioconjugation of GFP-G1 with cell penetrating peptide TAT and metal ion chelating agent DTPA was achieved using strain-promoted azide-alkyne cycloaddition (SPAAC) in a non-site-specific manner. GFP-G1 was buffer exchanged in $0.1 \mathrm{M} \mathrm{NaHCO}_{3} \mathrm{pH} 8.5$, concentrated to $25 \mu \mathrm{M}$ and 
reacted with a seven-fold molar excess of dibenzocyclooctyne-4-Sulfo-2,3,5,6-tetrafluorophenyl (DBCO-STP) (Click Chemistry Tools, USA) dissolved in dimethyl sulfoxide (DMSO) at room temperature for $4 \mathrm{~h}$. The antibody-DBCO conjugate was purified and buffer exchanged to PBS by centrifugal filtration using a Zeba Spin desalting column (7 K MWCO, $0.5 \mathrm{~mL}$, Thermo Scientific USA). The amount of DBCO tags conjugated to the antibody was determined by absorbance spectroscopy at 280 and $309 \mathrm{~nm}$, with a DBCO:antibody ratio of 5:1. The antibody-DBCO conjugate, at approximately $10 \mu \mathrm{M}$, was then reacted with a 2-fold molar equivalent relative to DBCO of 3.4 mM N3-Bn-DTPA dissolved in PBS + 20\% DMSO (Supplementary Fig 2; see supplemental info for full synthesis details), and, concurrently, a 0.5 -fold molar equivalent (relative to DBCO) of $1 \mathrm{mM}$ azide-tagged cell penetrating peptide TAT-AHA (GRKKRRQRRRPPQGYG-hA(N $\left.\mathrm{N}_{3}\right)$ dissolved in PBS, Cambridge Peptides, Birmingham, UK) at $4^{\circ} \mathrm{C}$ for $12 \mathrm{~h}$. The antibody conjugate was purified and buffer exchanged to $0.5 \mathrm{M}$ sodium citrate $\mathrm{pH} 5.4$ to remove unreacted products as previously described. The completion of the conjugation reaction was confirmed by the reduction of UV absorption spectrometry at $309 \mathrm{~nm}$ to background level.

Radiolabelling of immunoconjugates was carried out by addition of ${ }^{111} \mathrm{InCl}_{3}$ (Perkin Elmer, MA, USA). Aliquots of $150 \mu \mathrm{g}$ of IgG conjugate ( $1 \mathrm{mg} / \mathrm{mL}$ in $0.5 \mathrm{M}$ sodium citrate $\mathrm{pH} 5.4$ ) were reacted with ${ }^{111} \mathrm{InCl}_{3}(1 \mathrm{MBq} / \mu \mathrm{g}$ of antibody) in $0.5 \mathrm{M}$ sodium citrate buffer $\mathrm{pH} 5.4$ for $1 \mathrm{~h}$ at room temperature. Radiolabelling yield was determined by instant thin layer chromatography (iTLC) to be greater than $95 \%$. The resulting radiolabelled compound [ ${ }^{111}$ In]In-GFP-G1-TAT was buffer exchanged to PBS to remove free ${ }^{111} \mathrm{In}^{3+}$ prior to subsequent studies. 


\section{In vitro studies}

Aliquots of $8 \times 10^{4}$ cells/well were plated in a 24 well plate cell culture dishes and allowed to adhere for $16 \mathrm{~h}$. Culture medium was removed, and cells washed with PBS before addition of fresh culture medium containing $\left[{ }^{111} \mathrm{In}\right] \mathrm{In}-\mathrm{GFP}-\mathrm{G} 1-\mathrm{TAT}(1.5 \mathrm{nM}, 1 \mathrm{MBq} / \mu \mathrm{g})$ and incubation at $37^{\circ} \mathrm{C}$ for a further $60 \mathrm{~min}$. Supernatant containing unbound radiolabelled compound was collected, cells were washed twice with PBS before cells were washed for $5 \mathrm{~min}$ on ice in $0.1 \mathrm{M}$ glycine $\mathrm{pH} 2.5$ solution to remove membrane-bound radiolabelled antibody conjugate. Finally, cells were lysed by addition of $0.1 \mathrm{M} \mathrm{NaOH}$, and cell-associated compound was collected. The amount of ${ }^{111} \mathrm{In}$ within each fraction was determined by automated gamma counting (Wizard ${ }^{2} 2480$, Perkin Elmer), to calculate the percentage of cell-associated ${ }^{111} \mathrm{In}$.

\section{In vivo studies}

All animal procedures were carried out in accordance with the UK Animals (Scientific Procedures) Act 1986 and with local ethical committee approval. Animals were housed in IVC cages in sex matched groups of up to 6 per cage in an artificial day-night cycle facility with ad libitum access to food and water. No animals were culled for welfare reasons. Xenografts of H1299 cells, wild type or stably transfected with varying levels of H2B-EGFP, were established by subcutaneous inoculation of $10^{6}$ cells in a 1:1 (v/v) PBS:matrigel mix, on the right flank of female BALB/c $n u / n u$ mice (Envigo, IN, USA). After 3-4 weeks, tumors reached an average size of $180 \mathrm{~mm}^{3}$ and were used for subsequent studies.

$\left[{ }^{111} \mathrm{In}\right] \mathrm{In}-\mathrm{GFP}-\mathrm{G} 1-\mathrm{TAT}(5 \mathrm{MBq} / 5 \mu \mathrm{g})$ in PBS was administered to each mouse via the lateral tail vein. SPECT/CT images were acquired using a SPECT/CT scanner (VECTor ${ }^{4} \mathrm{CT}, \mathrm{MILabs,}$ 
Utrecht, the Netherlands) at 24 and $72 \mathrm{~h}$ after injection. Volume of interest (VOI) analysis on SPECT images was performed using PMOD (PMOD Technologies, Zürich, Switzerland). For full experimental details, reconstruction and acquisition parameters, see Supplemental Information (22). After imaging, mice were culled, and samples of blood and other selected organs were collected to determine the percentage of the injected dose per gram of tissue $(\% \mathrm{ID} / \mathrm{g})$ using a Hidex Automatic Gamma Counter (Hidex Oy, Turku, Finland). Tumor samples were immediately counted prior to flash freezing with dry ice before storage at $-80^{\circ} \mathrm{C}$ for future analysis.

\section{Statistical analysis}

All statistical analysis was carried out using GraphPad Prism v8 (GraphPad Software, San Diego, CA, USA). Linear regression with an extra sum of squares $\mathrm{F}$ test was used to determine the statistical significance of correlations between estimated regression parameters. One-way ANOVA with Tukey's post hoc test, or 2-way ANOVA was used to compare grouped data to compare individual group means, as appropriate. All data was collected at least in triplicate, and presented as mean \pm one standard deviation unless otherwise stated. 


\section{RESULTS}

\section{Generation of stably transfected H1299/H2B-EGFP cells}

To test the effects of target abundance on imaging ability, we generated a panel of H1299 cell lines that constitutively expressed Enhanced Green Fluorescent Protein (EGFP) tagged at its amino terminus with the histone protein $\mathrm{H} 2 \mathrm{~B}$ through stable transfection with the mammalian expression plasmid H2B-EGFP. Several colonies of H1299 cells stably expressing H2B-EGFP at various levels were generated and four were selected for future studies, named H2B-EGFP 45, 56, 61 and 62, as well as wild type (WT) H1299 cells. Expression levels of H2B-EGFP were measured by flow cytometry, and western blot (Figs 1A, B). Expression levels of H2B-EGFP were quantified by ELISA (Fig 1C), with expression levels ranging between 183,000 $\pm 4,900$ and 1,050,000 \pm 91,100 copies per cell. These results were corroborated by fluorescence confocal microscopy, which further confirmed exclusively nuclear EGFP expression (Fig 2A).

\section{The murine monoclonal antibody GFP-G1 selectively binds H2B-EGFP}

The murine monoclonal anti-GFP antibody GFP-G1 was characterised by flow cytometry with each selected H2B-EGFP transfected cell line along with a H1299 WT control, in fixed and permeabilised cells, confirming earlier results on its selectivity (Figs 2A, B) (23). Fluorescence intensity correlated linearly with H2B-EGFP expression, as measured by ELISA (Fig 2B, r = 0.87, $P<0.001)$. The specificity of GFP-G1 was further supported by immunofluorescence microscopy showing co-localisation of H2B-EGFP, GFP-G1 and the DNA stain DAPI (Fig 2A). Immunofluorescence microscopy also demonstrated a correlation between H2B-EGFP expression 
and GFP-G1 signal intensity. A flow cytometry-based saturation binding assay was used to determine the affinity $\left(\mathrm{K}_{\mathrm{D}}\right)$ of GFP-G1 for GFP as $9.1 \pm 3.0 \mathrm{nM}$ (Fig 2C).

\section{In vitro uptake of $\left[{ }^{111} \mathrm{In}\right] \mathrm{In}-\mathrm{GFP}-\mathrm{G1}-\mathrm{TAT}$ is correlated to nuclear GFP expression}

GFP-G1 was conjugated to the cell penetrating peptide TAT and metal ion chelating agent DTPA prior to radiolabelling with ${ }^{111} \mathrm{InCl}_{3}$ (Fig 3A). In vitro uptake assays showed that $\left[{ }^{111} \mathrm{In}\right] \mathrm{In}$-GFPG1-TAT uptake in the panel of five cell lines correlated linearly with increasing H2B-EGFP expression (Fig 3B, $\mathrm{r}=0.64, P<0.001$ ), suggesting that uptake was the result of specific binding between $\left[{ }^{111} \mathrm{In}\right]$ In-GFP-G1-TAT and intranuclear H2B-EGFP. In a comparison with a non-TAT modified [ $\left.{ }^{111} \mathrm{In}\right]$ In-GFP-G1, using the highest H2B-EGFP expressing H2B-EGFP 45 cell line, $\left[{ }^{111} \mathrm{In}\right] \mathrm{In}-\mathrm{GFP}-\mathrm{G} 1-\mathrm{TAT}$ showed a 6.8 fold increase in cell uptake (Supplementary Fig 3, $P=$ 0.026), demonstrating the requirement of the CPP TAT in the internalisation of the imaging probe. Finally, a colony formation assay was used to determine whether the uptake of $\left[{ }^{111} \mathrm{In}\right] \mathrm{In}-\mathrm{GFP}-\mathrm{G} 1$ TAT and the subsequent radiation dose affected cell viability. In both the H1299 WT and H2BGFP 45 cells, there was no significant difference in colony formation between cells exposed to $\left[{ }^{111} \mathrm{In}\right] \mathrm{In}-\mathrm{GFP}-\mathrm{G} 1-\mathrm{TAT}, \quad\left[{ }^{111} \mathrm{In}\right] \mathrm{In}-\mathrm{GFP}-\mathrm{G} 1$ without TAT, and an untreated control group (Supplementary Fig 4).

Tumor uptake of $\left[{ }^{111} \mathrm{In}\right] \mathrm{In}-\mathrm{GFP}-\mathrm{G1}-\mathrm{TAT}$ is correlated to nuclear GFP expression, and reveals the detection limit of IgG-TAT architecture

$\left[{ }^{111} \mathrm{In}\right] \mathrm{In}-\mathrm{GFP}-\mathrm{G} 1-\mathrm{TAT}$ could detect H2B-EGFP in a xenograft animal model, bearing tumors consisting of H2B-EGFP 45, 56, 62 and H1299 WT cells. Ex vivo biodistribution studies revealed 
a statistically significant linear correlation between tumor uptake of $\left[{ }^{111} \mathrm{In}\right] \mathrm{In}$-GFP-G1-TAT and expression of H2B-EGFP (Fig 4A, 4B r $=0.63, P=0.004)$, demonstrating that $\left[{ }^{111} \mathrm{In}\right] \mathrm{In}-\mathrm{GFP}-\mathrm{G} 1-$ TAT can quantitatively determine the level of H2B-EGFP expression within tumor xenografts in vivo. Interpolation of the linear regression model suggested a lower H2B-EGFP copy number threshold for detectable uptake of $\left[{ }^{111}\right.$ In]In-GFP-G1-TAT of approximately 240,000 copies/cell, which was higher than the predicted threshold in vitro (182,000 copies/cell). This was supported by the statistically significant difference in uptake between H1299 WT $(16.1 \pm 3.4 \% \mathrm{ID} / \mathrm{g})$ and H2B-EGFP $45(24.8 \pm 1.6 \% \mathrm{ID} / \mathrm{g} ; P=0.010)$ and H2B-EGFP $56(21.9 \pm 2.7 \% \mathrm{ID} / \mathrm{g} ; P=0.033)$. Interestingly, the uptake of H2B-EGFP $62(22.4 \pm 5.0 \% \mathrm{ID} / \mathrm{g})$ was also significantly higher than H1299 WT $(P=0.018)$, which implies that the detection threshold may even be lower.

Uptake of $\left[{ }^{111} \mathrm{In}\right] \mathrm{In}-\mathrm{GFP}-\mathrm{G} 1-\mathrm{TAT}$ with increasing expression of H2B-EGFP was also demonstrated visually by SPECT/CT imaging (Fig 5). Image quantification of uptake again showed a correlation between uptake and expression of H2B-EGFP at both $24 \mathrm{~h}(\mathrm{r}=0.66, P=$ $0.010)$ and $72 \mathrm{~h}(\mathrm{r}=0.68, P=0.002)$ after intravenous administration (Fig 6A, 6B). At $24 \mathrm{~h}$ after administration, interpolation of the linear regression model suggested lower detection threshold of 316,000. However, SPECT images at $72 \mathrm{~h}$ post administration suggested a lower detection threshold of 237,000 copies/cell, which reflected the results obtained with the biodistribution study. 


\section{DISCUSSION}

Antibody- or antibody fragment-based immuno-PET/SPECT imaging is a rapidly growing field, with an increasingly broad selection of radioisotopes to use along with a repertoire of highly sensitive and selective antibody- and antibody fragment-based vector systems that can be optimised for specific applications. The effectiveness of any antibody-based imaging probe can be reduced to three central factors (24). The first factor is target abundance, which must be suitably high to allow its detection within the tissue of interest. Secondly, the targeting component of the RIC, whether an antibody or antibody fragment must exclusively bind only to the epitope, with high affinity. Finally, the RIC must exhibit the pharmacokinetic and clearance characteristics in vivo that will allow it to develop a contrast with non-target tissues. In this study, we used a stable transfection reporter system to investigate the consequence of decreasing target abundance on RIC detection and imaging capacity.

We chose H2B-EGFP as a model target protein as it is a well characterised recombinant nuclearlocalised protein expression system that is capable of stable transfection $(20,25)$. In vitro assays demonstrated that $\left[{ }^{111} \mathrm{In}\right] \mathrm{In}-\mathrm{GFP}-\mathrm{G} 1-\mathrm{TAT}$ uptake correlated with expression level of H2B-EGFP with a predicted minimum detection threshold limit of approximately 182,000 copies/cell. Other reports, relying on quantitative mass spectrometry in U2OS and He-La cells, showed that up to a fifth of all nuclear proteins are expressed to this level, and thus may be visualised using a TATconjugated suitable antibody, although this analysis does not include pharmacologically or pathologically induced (over)expression of proteins $(26,27)$. The relatively small increase in [ ${ }^{111}$ In]In-GFP-G1-TAT uptake between H1299 WT and H2B-EGFP expressing cells in vitro was indicative of high levels of non-specific uptake, possibly as a result of modification with the TAT peptide. However, this system can be used to optimise a multitude of factors to increase specific 
RIC uptake, potentially lowering the effective detection threshold and improving the target abundance resolution of IgG-TAT-based imaging compounds.

The basis of an effective RIC imaging probe is a highly selective and sensitive antibody/fragment. We selected the GFP-G1 monoclonal antibody as there was a readily available and validated hybridoma cell line $(21,23)$, allowing for production and purification on a scale suitable for bioconjugation and subsequent radio-assays. Flow cytometry and immunofluorescence microscopy confirmed that GFP-G1 was highly specific and showed good affinity at $\mathrm{K}_{\mathrm{D}}=9.1 \pm$ $3.0 \mathrm{nM}$, comparable to clinically approved antibodies such as Trastuzumab (5.0 nM) (28). However, it should be noted that highly optimised antibodies or antibody-based constructs are capable of affinities in the sub picomolar range (29). An important consideration for future research is whether an antibody with greater affinity could improve the detection threshold and resolution by reducing the signal to noise ratio.

The conjugation of functional groups, such as TAT and DTPA can considerably alter the characteristics of a RIC. At the cellular level, the addition of TAT facilitates the transport of the RIC across the cellular membrane. However, due to the highly cationic nature of TAT, TATmodified RICs can result in significant increases in non-specific binding. One of the primary factors that could control the detection threshold and degree of non-specific uptake is the mechanism of IgG-TAT internalisation into cells. CPPs have been shown to facilitate the internalisation of wide array of cargo proteins, which is believed to be largely driven by endocytosis under physiological conditions (30). However, due to the complex array of CPPs and CPP-cargo combinations (31), attempts to establish the principle endocytic mechanisms involved have proved ambiguous, suggesting that CPPs can utilise distinct endocytic pathways. One major factor governing the efficiency of internalisation under physiological conditions is molecular mass 
of the cargo protein cargo size (32). Larger cargo proteins, such as whole antibodies, are internalised at significantly lower efficiencies in comparison to small cargo proteins, potentially caused by induction of alternative cell internalisation mechanisms $(31,33,34)$.

Another major challenge facing CPP-mediated intranuclear imaging is non-specific uptake due to endosomal entrapment, resulting in high cellular uptake but poor cytosolic availability and subsequent target engagement. The recent development of cyclic derivatives of TAT and polyarginine CPPs have demonstrated not only dramatic increases in cell uptake of cargo proteins (35), but also significantly improved cytosolic availability in comparison to the linear CPPs (36). This model system provides an excellent opportunity to investigate the effects of such optimisations for specific cellular uptake of targeted RICs.

Finally, the choice of chelating agent and radioisotope can also affect the sensitivity and degree of non-specific tumor uptake. As the principle objective of this study was to investigate the biodistribution and pharmacokinetic properties of an IgG-TAT RIC, DTPA was used to chelate ${ }^{111}$ In for simplicity of radiolabelling and to maintain consistency with previous research using TAT-antibody imaging agents. Radiometal-chelate stability is important when using a nucleus targeted RIC, so as to prevent non-specific sequestration of the radiometal and limit subsequent off-target radiation dose, especially when working with an Auger electron emitting isotope, such as ${ }^{111}$ In (37). Alternative chelating agents, for instance CHX-A"-DTPA, have greater stability in vivo and therefore could be used to chelate ${ }^{111}$ In (38). For clinical use, PET has several advantages over SPECT, including greater sensitivity, easier scatter correction and capacity to provide quantitative results (39). Therefore, to increase the potential for clinical translation, future research will be focused on combining this technology with long half-life PET isotopes, such as ${ }^{89} \mathrm{Zr}$ in conjunction with a suitable chelating agent, such as desferrioxamine B. 
In vivo, both biodistribution and quantitative image analysis indicated that the minimum detection threshold was 240,000 copies/cells, which was predictably higher than the threshold obtained from in vitro studies. The reason for the higher observed threshold in vivo may be attributed to increased non-specific tumor uptake as a result of the enhanced permeability and retention (EPR) effect and blood background signal, presenting an additional source of non-specific signal (40). This effect is exacerbated not only by the molecular mass of TAT-IgG based imaging probes but also the presence of a functional Fc domain, which promotes extended blood uptake through FcRn mediated recycling (41). In comparison, smaller antibody fragment-based RICs without a functional Fc domain show a rapid reduction in blood uptake through the renal clearance pathway and lack of FcRn mediated recycling, potentially reducing non-specific uptake. Using $\left[{ }^{111} \mathrm{In}\right] \mathrm{In}$ GFP-G1-TAT derived smaller antibody fragments may improve sensitivity both in vitro and in vivo. EGFP-targeted imaging is an ideal platform for the evaluation of such optimisations to RICs.

This work was aimed at guiding research into evaluation of novel intracellular or intranuclear imaging targets. In the context of previous antibody-based PET/SPECT imaging, $\gamma \mathrm{H} 2 \mathrm{AX}$ is probably the most documented and has an approximate cell abundance of approximately 800,000 copies per cell at maximum, in an irradiated cell (17), depending on several factors such as cell line and extent of DNA damage prior to administration of the tracer. Expression levels of proteins we targeted before, such as p21 and p27 levels may be below the threshold we determined here for GFP. Approximations for these proteins may range from $10^{4}-10^{5}$ copies/cell at baseline in normal tissue (27), although little quantitative data is available, and levels will oscillate throughout the cell cycle. Whilst in this piece of research, we calculated a lower detection limit of approximately $2.4 \times 10^{5}$ copies per cell, we acknowledge that this value is specific to this simplified model system and cannot be treated as an absolute. Therefore, it is important to take into account the myriad of 
factors that can influence the lower detection threshold, such as RIC affinity, CPP selection, and variation in target expression levels and subcellular location when considering potential candidates for imaging. This model system, however, is an endeavour to establish an approximate base line and subsequent research will exploit variations of this model to investigate the impact of these factors on the detection capacity of antibody- or antibody fragment- based intracellular imaging.

In summary, this study presents a proof of concept methodology set out to evaluate, quantitatively, the practical limitations of antibody-based intranuclear immuno-PET/SPECT imaging. We confirmed the current capacity of imaging an intranuclear epitope with a TAT-conjugated intact antibody. This framework could in the future be used to methodically isolate, interrogate and optimise a variety of factors that define the efficacy of antibody based imaging devises, potentially leading to the development of more powerful whole-body immuno-imaging devices.

\section{Competing Financial Interests}

The authors declare that they have no conflicting interests.

\section{Acknowledgments}

The authors thank MRC and CRUK for financial support, through grants MC_ST_OIRO_2019 and 23970 , respectively. 


\section{Key Points}

\section{QUESTION:}

What is the lowest detection threshold for successful imaging of an intranuclear epitopes using IgG-TAT based radioimmunoconjugates?

\section{PERTINENT FINDINGS:}

We developed a model system to test, and improve, the lower target abundance threshold using IgG-TAT based PET/SPECT imaging, revealing a current lower detection limit of 180,000 copies/cell in vitro, and 240,000 copies/cell in vivo.

\section{IMPLICATIONS FOR PATIENT CARE:}

This model system can be used to evaluate and improve intranuclear PET/SPECT imaging, with great potential for the development of a range of clinical applications not currently possible. 


\section{REFERENCES}

1. James ML, Gambhir SS. A molecular imaging primer: modalities, imaging agents, and applications. Physiol Rev. 2012;92:897-965.

2. Freise $\mathrm{AC}, \mathrm{Wu} \mathrm{AM}$. In vivo imaging with antibodies and engineered fragments. Mol Immunol. 2015;67:142-152.

3. Shaiken TE, Opekun AR. Dissecting the cell to nucleus, perinucleus and cytosol. Sci Rep. 2014;4:4923.

4. Guidotti G, Brambilla L, Rossi D. Cell-Penetrating Peptides: From Basic Research to Clinics. Trends Pharmacol Sci. 2017;38:406-424.

5. Ye J, Liu E, Yu Z, et al. CPP-Assisted Intracellular Drug Delivery, What Is Next? Int J Mol Sci. 2016;17.

6. Frankel AD, Pabo CO. Cellular uptake of the tat protein from human immunodeficiency virus. Cell. 1988;55:1189-1193.

7. Green M, Loewenstein PM. Autonomous functional domains of chemically synthesized human immunodeficiency virus tat trans-activator protein. Cell. 1988;55:1179-1188.

8. Joliot A, Pernelle C, Deagostini-Bazin H, Prochiantz A. Antennapedia homeobox peptide regulates neural morphogenesis. Proc Natl Acad Sci U S A. 1991;88:1864-1868.

9. Agrawal P, Bhalla S, Usmani SS, et al. CPPsite 2.0: a repository of experimentally validated cellpenetrating peptides. Nucleic Acids Res. 2016;44:D1098-1103. 
10. Keller AA, Mussbach F, Breitling R, et al. Relationships between Cargo, Cell Penetrating Peptides and Cell Type for Uptake of Non-Covalent Complexes into Live Cells. Pharmaceuticals (Basel). $2013 ; 6: 184-203$.

11. Hu M, Chen P, Wang J, Scollard DA, Vallis KA, Reilly RM. 123I-labeled HIV-1 tat peptide radioimmunoconjugates are imported into the nucleus of human breast cancer cells and functionally interact in vitro and in vivo with the cyclin-dependent kinase inhibitor, p21(WAF-1/Cip-1). Eur J Nucl Med Mol Imaging. 2007;34:368-377.

12. Cornelissen B, Kersemans V, McLarty K, Tran L, Vallis KA, Reilly RM. In vivo monitoring of intranuclear p27(kip1) protein expression in breast cancer cells during trastuzumab (Herceptin) therapy. Nucl Med Biol. 2009;36:811-819.

13. Cornelissen B, Able S, Kartsonaki C, et al. Imaging DNA damage allows detection of preneoplasia in the BALB-neuT model of breast cancer. $J$ Nucl Med. 2014;55:2026-2031.

14. Knight JC, Mosley MJ, Bravo LC, et al. (89)Zr-anti-gammaH2AX-TAT but not (18)F-FDG Allows Early Monitoring of Response to Chemotherapy in a Mouse Model of Pancreatic Ductal Adenocarcinoma. Clin Cancer Res. 2017;23:6498-6504.

15. Knight JC, Topping C, Mosley M, et al. PET imaging of DNA damage using (89)Zr-labelled antigammaH2AX-TAT immunoconjugates. Eur J Nucl Med Mol Imaging. 2015;42:1707-1717.

16. Knight JC, Baguna Torres J, Goldin R, et al. Early Detection in a Mouse Model of Pancreatic Cancer by Imaging DNA Damage Response Signalling. J Nucl Med. 2019.

17. Cornelissen B, Kersemans V, Darbar S, et al. Imaging DNA damage in vivo using gammaH2AXtargeted immunoconjugates. Cancer Res. 2011;71:4539-4549.

18. Kenanova V, Barat $\mathrm{B}$, Olafsen $\mathrm{T}$, et al. Recombinant carcinoembryonic antigen as a reporter gene for molecular imaging. Eur J Nucl Med Mol Imaging. 2009;36:104-114. 
19. Rosestedt M, Andersson KG, Mitran B, et al. Affibody-mediated PET imaging of HER3 expression in malignant tumours. Sci Rep. 2015;5:15226.

20. Kanda T, Sullivan KF, Wahl GM. Histone-GFP fusion protein enables sensitive analysis of chromosome dynamics in living mammalian cells. Curr Biol. 1998;8:377-385.

21. Yamagata M, Sanes JR. Transgenic strategy for identifying synaptic connections in mice by fluorescence complementation (GRASP). Front Mol Neurosci. 2012;5:18.

22. Kersemans V, Gilchrist S, Wallington S, et al. A Carbon-Fiber Sheet Resistor for MR-, CT-, SPECT-, and PET-Compatible Temperature Maintenance in Small Animals. Tomography. 2019;5:274-281.

23. Donate-Macian P, Alvarez-Marimon E, Sepulcre F, Vazquez-Ibar JL, Peralvarez-Marin A. The Membrane Proximal Domain of TRPV1 and TRPV2 Channels Mediates Protein(-)Protein Interactions and Lipid Binding In Vitro. Int J Mol Sci. 2019;20.

24. Reddy S, Robinson MK. Immuno-positron emission tomography in cancer models. Semin Nucl Med. 2010;40:182-189.

25. Liu S, Kwon M, Mannino M, et al. Nuclear envelope assembly defects link mitotic errors to chromothripsis. Nature. 2018;561:551-555.

26. Beck M, Schmidt A, Malmstroem J, et al. The quantitative proteome of a human cell line. Mol Syst Biol. 2011;7:549.

27. Bekker-Jensen DB, Kelstrup CD, Batth TS, et al. An Optimized Shotgun Strategy for the Rapid Generation of Comprehensive Human Proteomes. Cell Syst. 2017;4:587-599 e584. 
28. De Lorenzo C, Cozzolino R, Carpentieri A, Pucci P, Laccetti P, D'Alessio G. Biological properties of a human compact anti-ErbB2 antibody. Carcinogenesis. 2005;26:1890-1895.

29. Maynard J, Georgiou G. Antibody engineering. Annu Rev Biomed Eng. 2000;2:339-376.

30. Duchardt F, Fotin-Mleczek M, Schwarz H, Fischer R, Brock R. A comprehensive model for the cellular uptake of cationic cell-penetrating peptides. Traffic. 2007;8:848-866.

31. Tunnemann G, Martin RM, Haupt S, Patsch C, Edenhofer F, Cardoso MC. Cargo-dependent mode of uptake and bioavailability of TAT-containing proteins and peptides in living cells. FASEB J. 2006;20:1775-1784.

32. Ruseska I, Zimmer A. Internalization mechanisms of cell-penetrating peptides. Beilstein $J$ Nanotechnol. 2020;11:101-123.

33. Mussbach F, Franke M, Zoch A, Schaefer B, Reissmann S. Transduction of peptides and proteins into live cells by cell penetrating peptides. J Cell Biochem. 2011;112:3824-3833.

34. Barany-Wallje E, Gaur J, Lundberg P, Langel U, Graslund A. Differential membrane perturbation caused by the cell penetrating peptide Tp10 depending on attached cargo. FEBS Lett. 2007;581:2389-2393.

35. Patel SG, Sayers EJ, He L, et al. Cell-penetrating peptide sequence and modification dependent uptake and subcellular distribution of green florescent protein in different cell lines. Sci Rep. 2019;9:6298.

36. Nischan N, Herce HD, Natale F, et al. Covalent attachment of cyclic TAT peptides to GFP results in protein delivery into live cells with immediate bioavailability. Angew Chem Int Ed Engl. 2015;54:19501953.

37. $\mathrm{Ku} \mathrm{A}$, Facca VJ, Cai Z, Reilly RM. Auger electrons for cancer therapy - a review. EJNMMI Radiopharmacy and Chemistry. 2019;4:27. 
38. Price EW, Orvig C. Matching chelators to radiometals for radiopharmaceuticals. Chem Soc Rev. 2014;43:260-290.

39. Rahmim A, Zaidi H. PET versus SPECT: strengths, limitations and challenges. Nucl Med Commun. 2008;29:193-207.

40. Maeda H, Nakamura H, Fang J. The EPR effect for macromolecular drug delivery to solid tumors: Improvement of tumor uptake, lowering of systemic toxicity, and distinct tumor imaging in vivo. Adv Drug Deliv Rev. 2013;65:71-79.

41. Pyzik M, Rath T, Lencer WI, Baker K, Blumberg RS. FcRn: The Architect Behind the Immune and Nonimmune Functions of IgG and Albumin. J Immunol. 2015;194:4595-4603. 

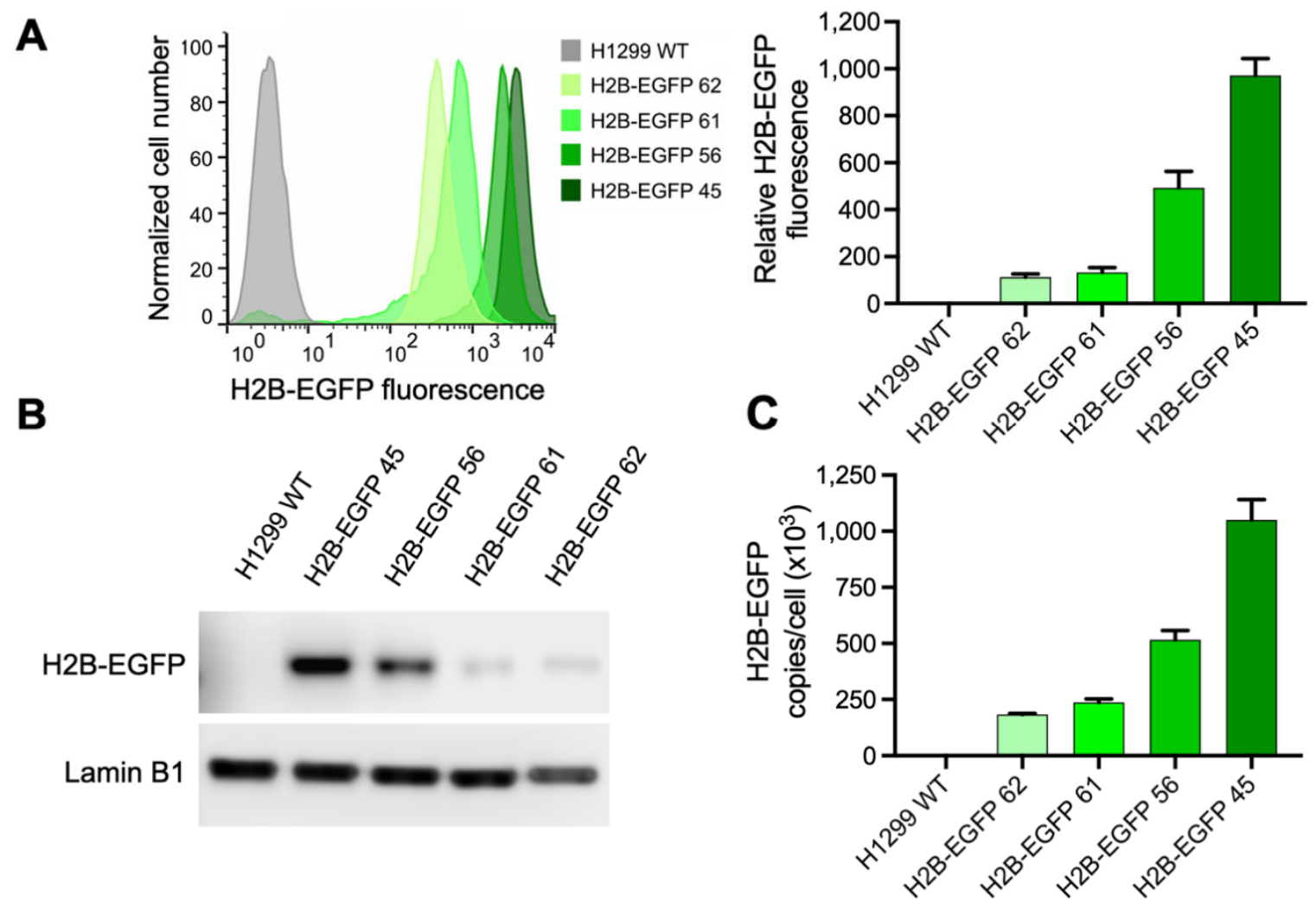

Figure 1: Establishment of H1299 cell lines stably transfected with H2B-EGFP. A) Relative difference in H2B-EGFP expression across all transfected cell lines, determined by flow cytometry and presented as a batch normalised bar chart. B) Confirmation of difference in H2B-EGFP expression across transfected cell lines using Western blot. C) Copy number per cell of H2B-EGFP in each transfected cell line, quantified by ELISA. 

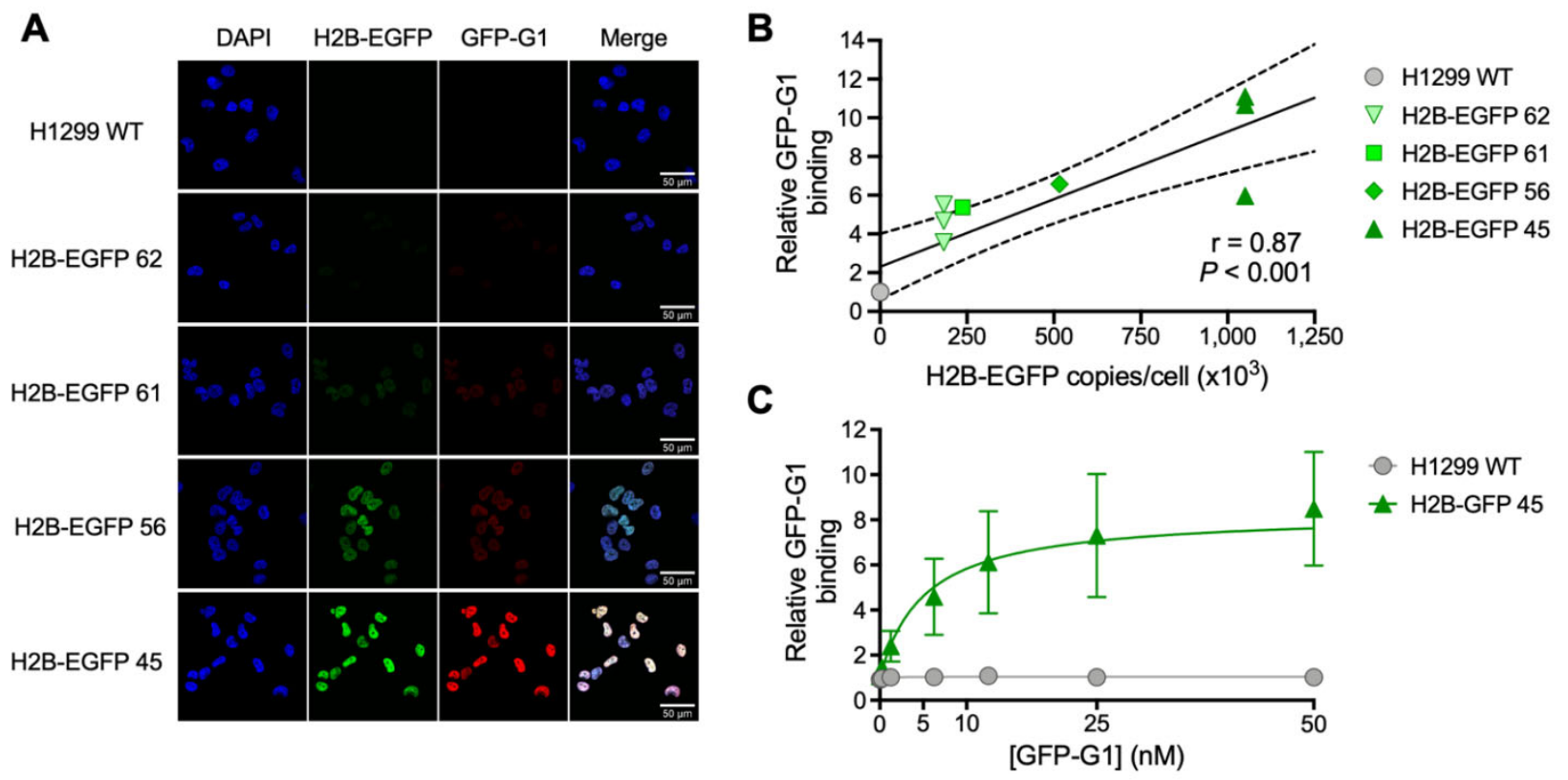

Figure 2: Validation and characterisation of GFP-G1 monoclonal antibody. A) Immunofluorescence microscopy showing colocalisation between H2B-EGFP expression and GFP-G1 monoclonal antibody. B) Confirmation of correlation between increasing H2B-EGFP expression and binding of monoclonal antibody GFP-G1, using flow cytometry. C) Determination of the dissociation constant $\left(\mathrm{K}_{\mathrm{D}}\right)$ of GFP-G1 with a flow cytometry-based saturation binding assay. 
A

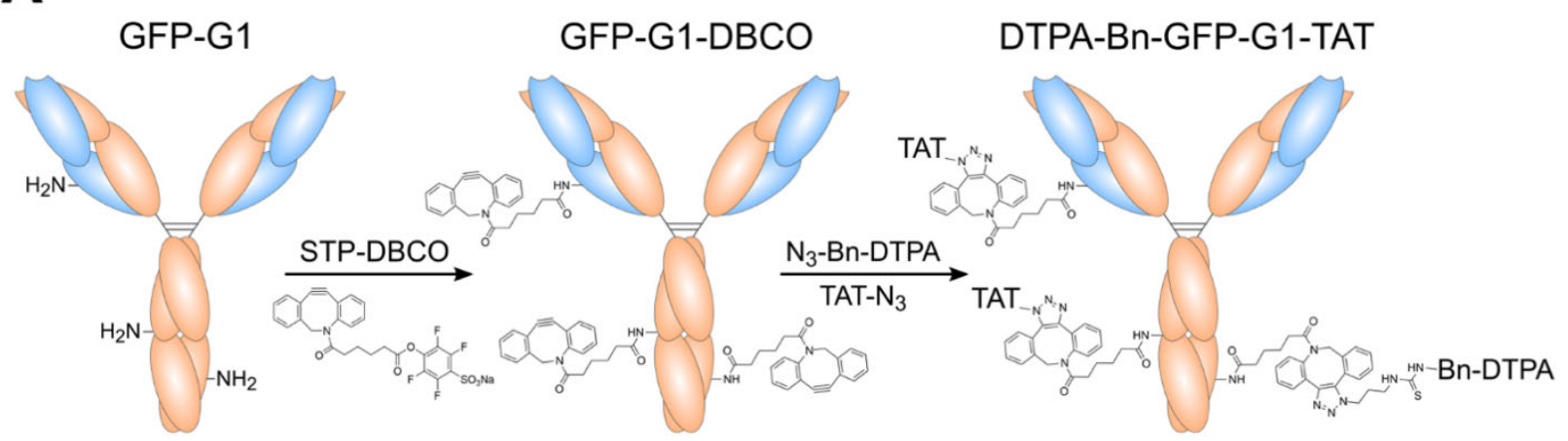

B

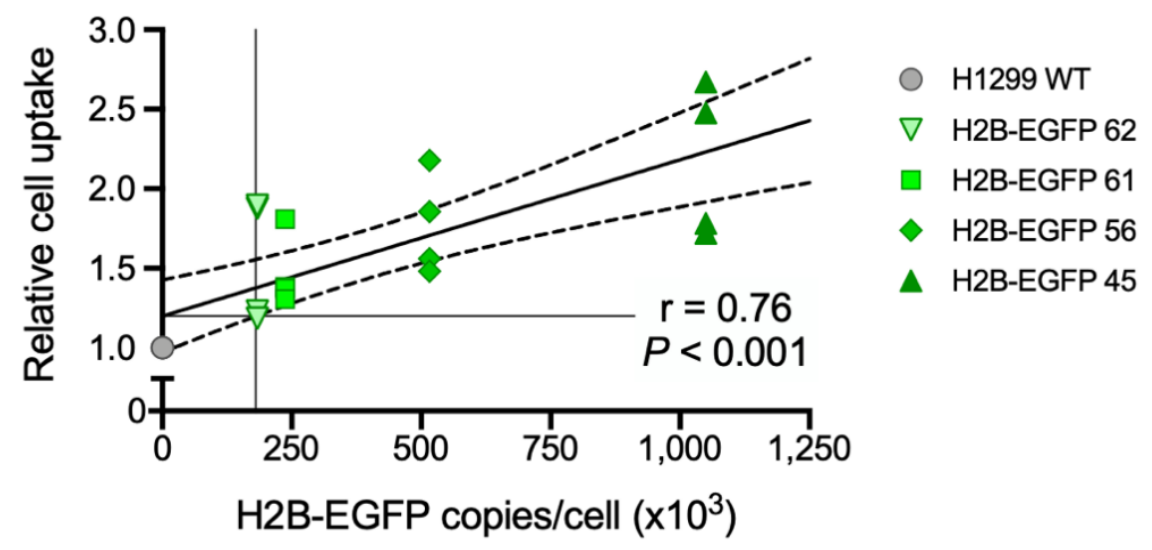

Figure 3: Conjugation and in vitro evaluation of $\left[{ }^{111}\right.$ In]In-GFP-G1-TAT uptake. A) Schematic diagram outlaying the approach to conjugate monoclonal antibody GFP-G1 with the CPP TAT and chelating agent Bn-DTPA using SPAAC based click chemistry. B) In vitro radiointernalisation assay revealing the correlation between $\left[{ }^{111} \mathrm{In}\right] \mathrm{In}-\mathrm{GFP}-\mathrm{G} 1-\mathrm{TAT}$ uptake and H2BEGFP expression. 


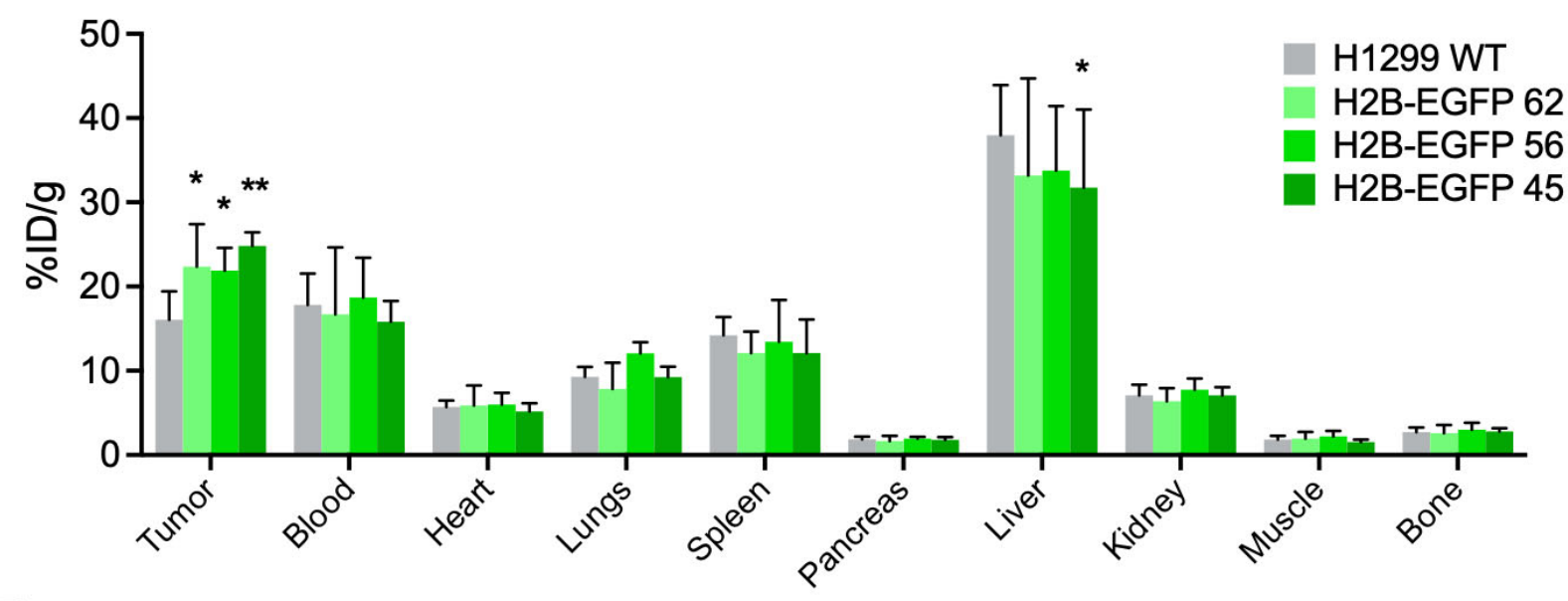

B

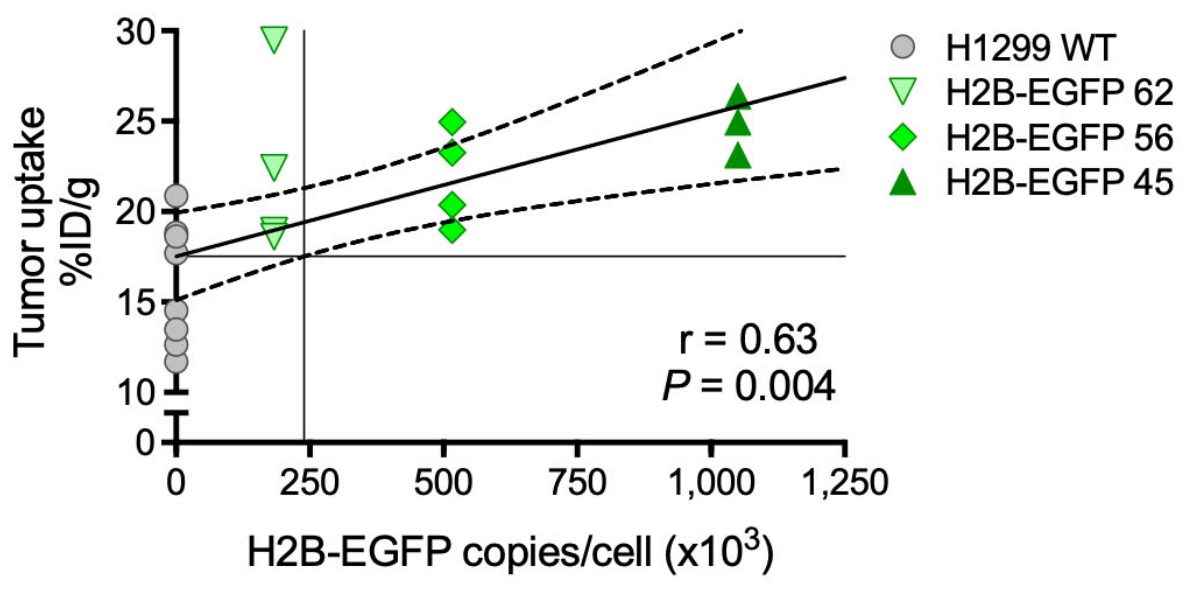

Figure 4: Ex vivo biodistribution and tumor uptake of [111In]In-GFP-G1-TAT. A) Ex vivo biodistribution showing the uptake of $\left[{ }^{111} \mathrm{In}\right] \mathrm{In}-\mathrm{GFP}-\mathrm{G} 1-\mathrm{TAT}$ in selected tissues and blood, $72 \mathrm{~h}$ after intravenous administration. B) Tumor uptake of $\left[{ }^{111} \mathrm{In}\right] \mathrm{In}-\mathrm{GFP}-\mathrm{G} 1-\mathrm{TAT}$ in vivo correlated linearly with expression of H2B-EGFP. Asterisks denote statistically significant differences in uptake from the H1299 WT group (* $\mathrm{P}<0.05 ; * * \mathrm{P}<0.01)$. 


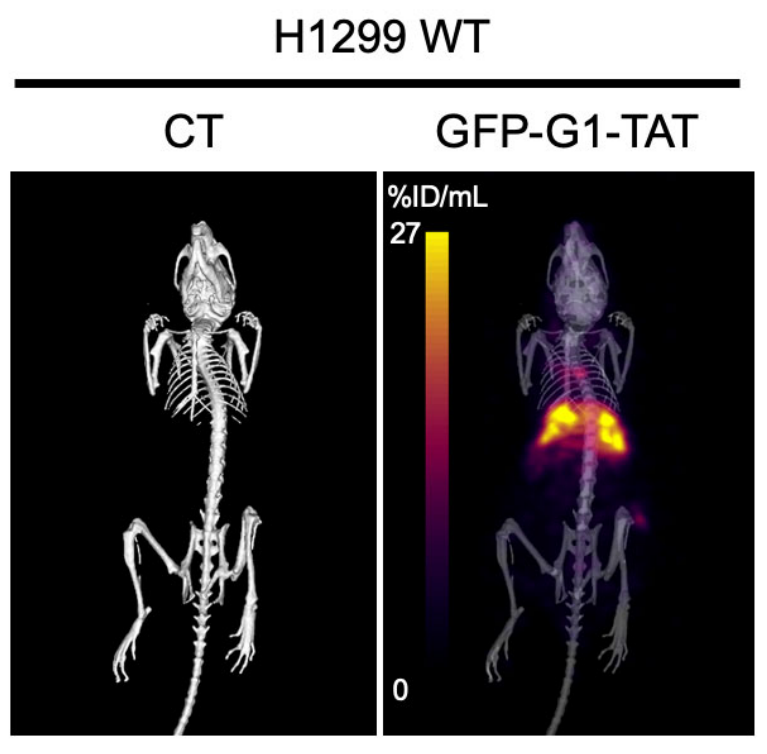

H2B-EGFP 56

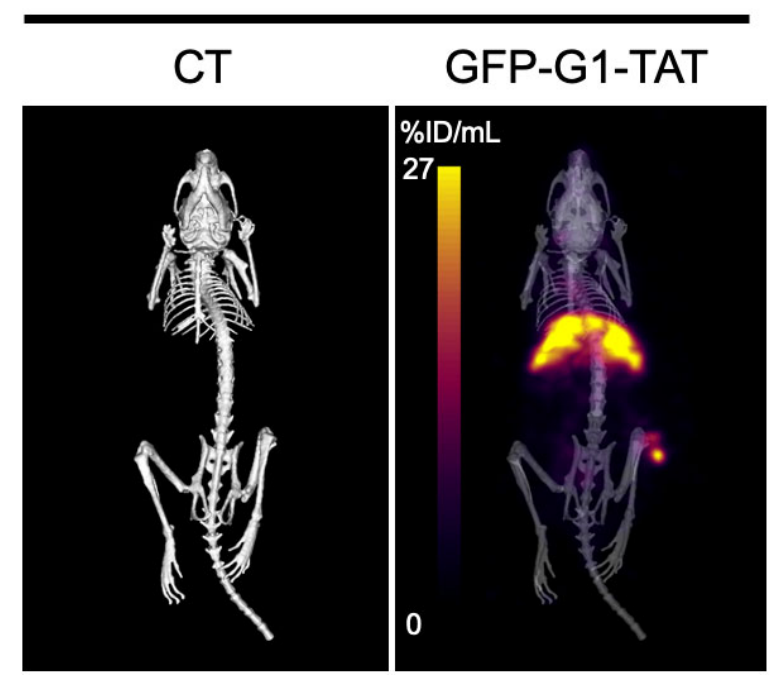

\section{H2B-EGFP 62}

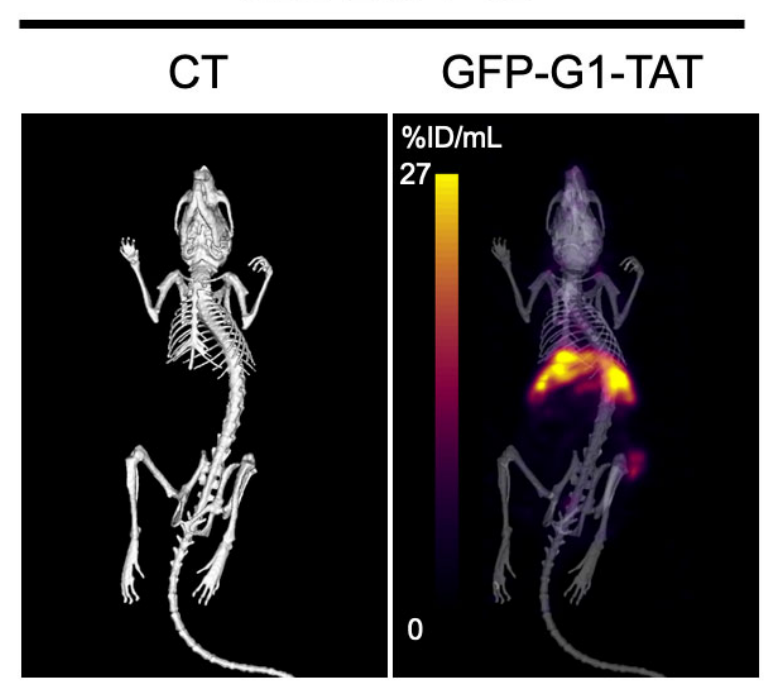

H2B-EGFP 45

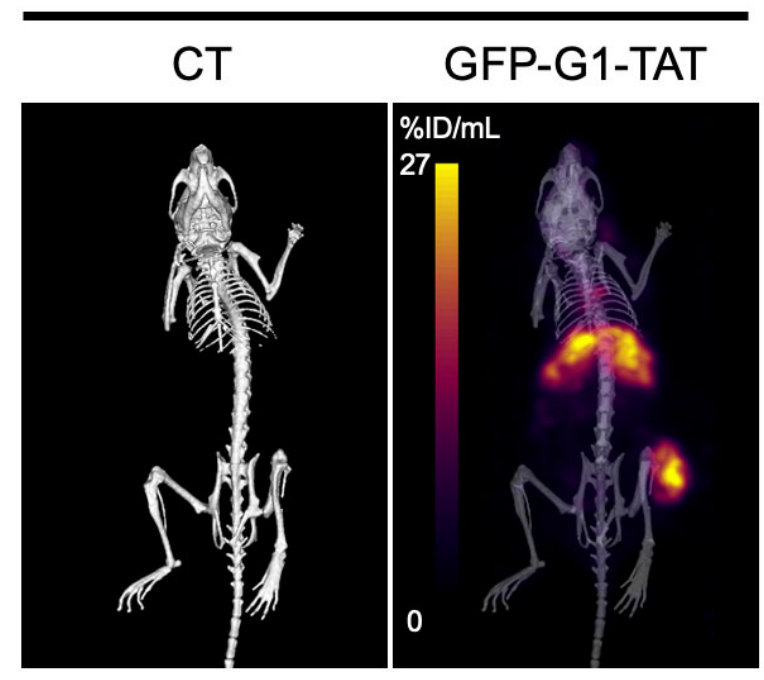

Figure 5: Imaging of [ ${ }^{111}$ In]In-GFP-G1-TAT in vivo. Representative CT and SPECT images showing distribution of $\left[{ }^{111} \mathrm{In}\right] \mathrm{In}-\mathrm{GFP}-\mathrm{G} 1-\mathrm{TAT}$ in mice bearing H2B-EGFP transfected H1299 cells, $72 \mathrm{~h}$ after intravenous administration. 
A

$24 \mathrm{~h}$

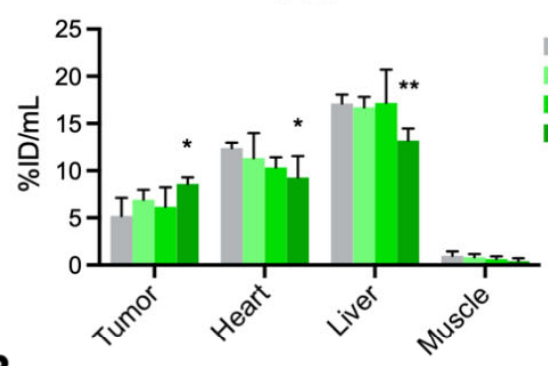

B

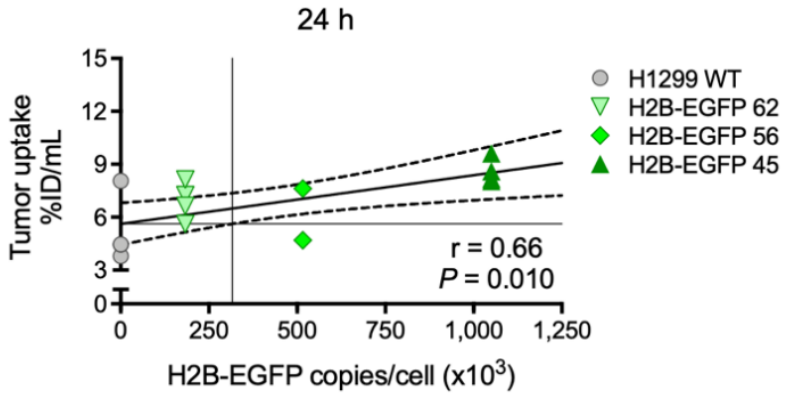

$72 \mathrm{~h}$

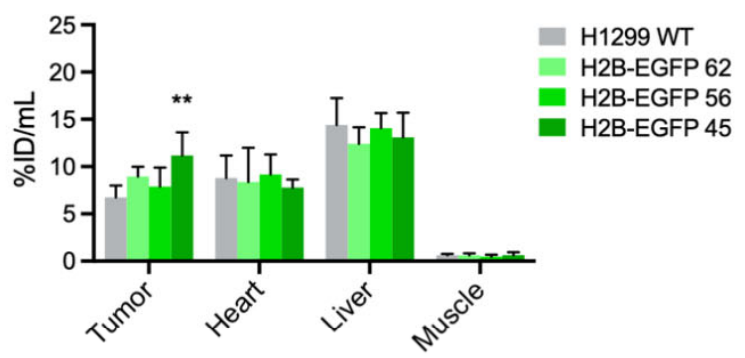

$72 \mathrm{~h}$

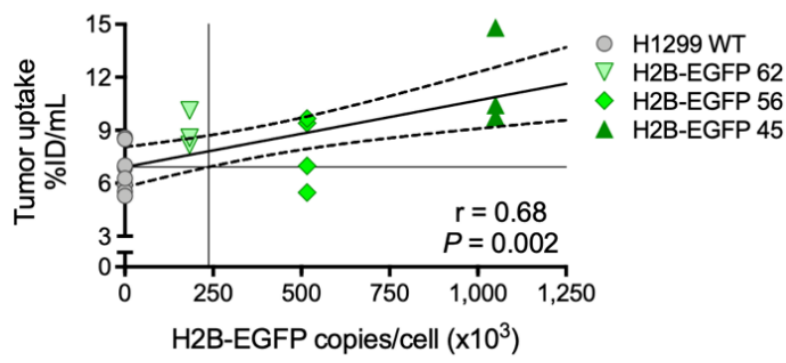

Figure 6: Image quantification analysis of [ ${ }^{111}$ In]In-GFP-G1-TAT biodistribution in vivo. A) Image quantification analysis showing uptake of [111In]In-GFP-G1-TAT in selected tissues, $24 \mathrm{~h}$ and $72 \mathrm{~h}$ after intravenous administration. B) Correlation of quantified tumor uptake with expression of H2B-EGFP, $24 \mathrm{~h}$ and $72 \mathrm{~h}$ after intravenous administration. Asterisks denote statistically significant differences in uptake from the H1299 WT group $\left({ }^{*} \mathrm{P}<0.05 ; * * \mathrm{P}<0.01\right.$, $* * * \mathrm{P}<0.001)$ 


\section{Graphical Abstract}

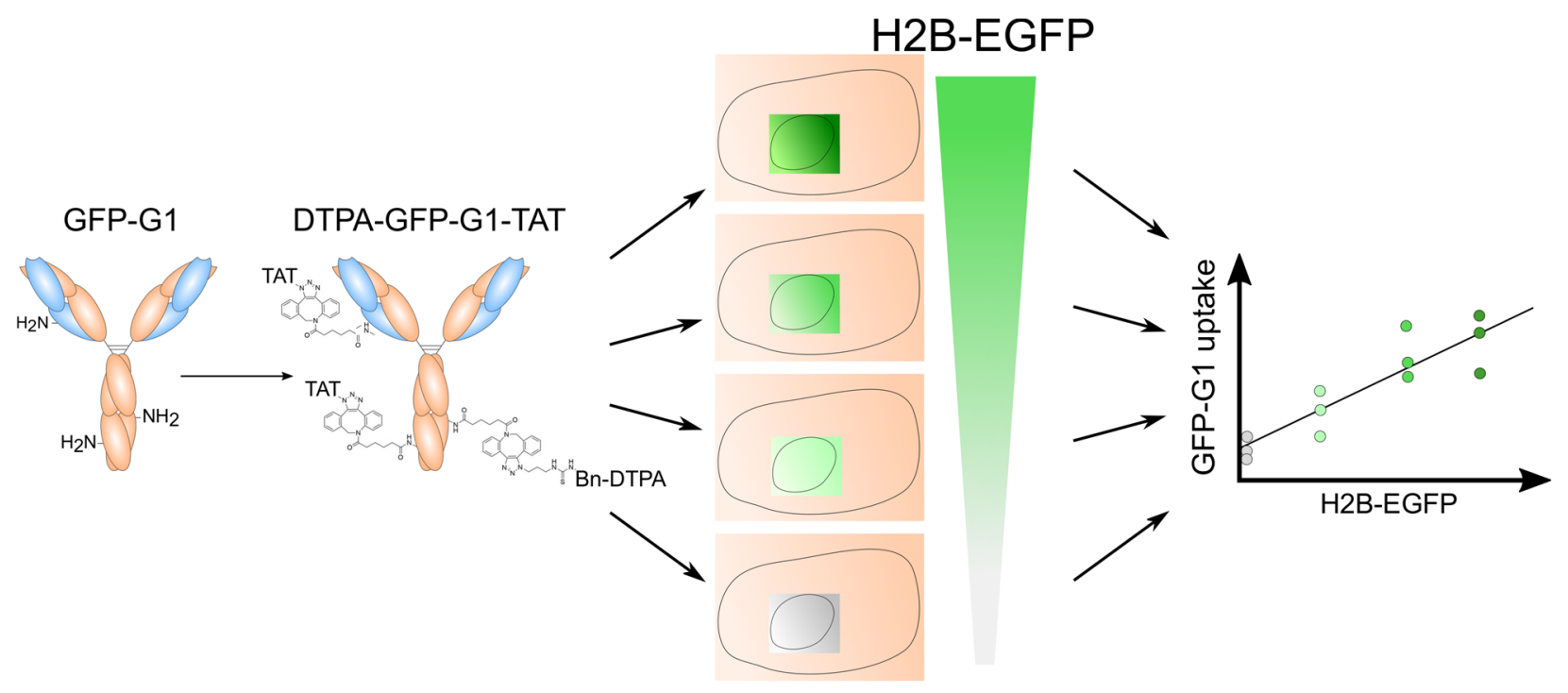




\section{Supplemental Information for}

\section{Exploring the detection limits of antibody-based Immuno-PET/SPECT Molecular Imaging of Intranuclear Proteins}

Mathew Veal ${ }^{1}$, Gemma Dias ${ }^{1}$, Veerle Kersemans ${ }^{1}$, Deborah Sneddon ${ }^{1,2}$, Stephen Faulkner ${ }^{2}$, and Bart Cornelissen ${ }^{1 *}$

${ }^{1}$ Medical Research Council Oxford Institute for Radiation Oncology, Department of Oncology, University of Oxford, UK

${ }^{2}$ Department of Chemistry, University of Oxford, UK

\section{Supplemental Materials \& Methods}

\section{Western blot}

Aliquots of $1.2 \times 10^{5}$ cells were plated in 6 well plates with complete culture medium and incubated overnight at $37^{\circ} \mathrm{C}$ with $5 \% \mathrm{CO}_{2}$. Cells were placed on ice and washed twice in ice cold PBS before lysis by addition of $100 \mu \mathrm{l}$ RIPA buffer (50 mM Tris-HCl, pH 8.0, $150 \mathrm{mM} \mathrm{NaCl,} \mathrm{1 \%} \mathrm{Triton} \mathrm{X-}$ 100, 0.5\% sodium deoxycholate) plus cOmplete ${ }^{\mathrm{TM}}$ EDTA-free Protease Inhibitor Cocktail (Sigma, Dorset, UK). Lysates were collected and set on ice for $20 \mathrm{~min}$ with vortexing every $5 \mathrm{~min}$. Lysates were clarified by centrifugation $\left(30 \mathrm{~min}, 16,000 \mathrm{x} \mathrm{g}, 4^{\circ} \mathrm{C}\right)$ and protein concentration of supernatants was determined using a colourimetric bicinchoninic acid assay (BCA) (Sigma, Dorset, UK) prior to storage a $-20^{\circ} \mathrm{C}$ until required. Lysates were reduced and linearised by the addition of 2X Laemmli sample loading buffer (4\% SDS, 20\% glycerol, 120 mM Tris-HCl pH 8.6, $0.02 \% \mathrm{w} / \mathrm{v}$ bromophenol blue) and heated to $96^{\circ} \mathrm{C}$ for 5 minutes prior to loading for separation on pre-cast SDS-PAGE gels (Thermo Scientific, MA, USA). Separated proteins were transferred onto a polyvinylidene fluoride (PVDF) membrane using an XCell II $^{\mathrm{TM}}$ Blot Module according to 
manufacturer protocol (Invitrogen, CA, USA). Transferred membranes were rinsed in Tris buffered saline (TBS) pH 7.4 and blocked in blocking buffer (5\% milk powder dissolved in TBS $+0.1 \%$ Tween-20 (TBST)) for $1 \mathrm{~h}$ at room temperature. Membranes were incubated with primary antibody in blocking buffer overnight at $4^{\circ} \mathrm{C}$. Membranes were then washed $3 \times 15 \mathrm{~min}$ in TBST, incubated with HRP conjugated secondary antibody for $1 \mathrm{~h}$ at room temperature and washed $3 \mathrm{x}$ 15 min again in TBST. Membranes were developed by addition of Pierce ${ }^{\mathrm{TM}}$ ECL Western Blotting Substrate (Thermo Scientific, MA, USA) and chemiluminescence was detected using C-DiGit ${ }^{\circledR}$ Blot Scanner (LI-COR, NE, USA).

\section{Flow cytometry}

Aliquots of $2 \times 10^{6}$ cells were plated in a T175 cell culture flask with complete culture medium and incubated overnight at $37^{\circ} \mathrm{C}$ with $5 \% \mathrm{CO}_{2}$. Cells were washed twice in ice cold PBS and collected by scraping followed by another wash by centrifugation ( $400 \mathrm{x} \mathrm{g}, 5 \mathrm{~min})$. Cells were fixed by incubation in PBS containing $4 \%$ paraformaldehyde (PFA) at $37^{\circ} \mathrm{C}$ for 10 min followed by washing by centrifugation in PBS. Fixed cells were permeabilised by addition of $0.25 \%$ Triton $\mathrm{X}-100$ in PBS at $4{ }^{\circ} \mathrm{C}$ for 20 min and washed again in PBS prior to blocking in flow cytometry blocking buffer (PBS containing 2\% foetal bovine serum (FBS)) for one hour at room temperature, then washed in PBS and incubated for $2 \mathrm{~h}$ at room temperature with primary antibody in flow cytometry blocking buffer at the desired concertation. Stained cells were washed with PBS before incubation for $1 \mathrm{~h}$ at room temperature with an appropriate fluorophore conjugated secondary antibody. Data was acquired using Invitrogen Attune NxT flow cytometer (Invitrogen, CA, USA). Data analysis was carried out using FlowJo ${ }^{\mathrm{TM}}$ v10.6.2 (FlowJo LLC, OR, USA). 20,000 events were counted per sample and plotted side scatter height (SSC-H) vs forward scatter height (FSC- 
H) to gate the cell population and exclude cell debris. From this population, doublet cells were excluded by correlation of forward scatter width (FSC-W) and side scatter area (FSC-A). The intensity of the appropriate fluorophore (H2B-EGFP or Alexa Fluor 594) was plotted on a logarithmic scale against normalised cell count. Geometric mean fluorescence intensities were calculated for each sample for further quantification analysis.

\section{Immunofluorescence microscopy}

$2 \times 10^{4}$ cells were plated in 8 well chambered tissue culture slides (Fisher Scientific, NH, USA) with complete culture medium and incubated overnight at $37^{\circ} \mathrm{C}$ and $5 \% \mathrm{CO}_{2}$. Cells were rinsed three times in ice cold PBS twice before fixation by addition of PBS containing $4 \%$ paraformaldehyde (PFA) at $37^{\circ} \mathrm{C}$ for 10 min followed by washing with PBS. Cells were then permeabilised by addition of $0.2 \%$ Triton $\mathrm{X}-100$ at $4^{\circ} \mathrm{C}$ for $20 \mathrm{~min}$ and washed again with PBS. Blocking solution of PBS $+2 \%$ FBS was added for $1 \mathrm{~h}$ at room temperature before washing in PBS and addition of blocking solution with the primary antibody at the desired concentration, which was incubated at $4^{\circ} \mathrm{C}$ overnight. The primary antibody solution was removed and cells washed three times in PBS for 15 min before addition of blocking solution containing the appropriate secondary antibody for 1 hour at room temperature. Stained cells were then washed three times in PBS for 15 min before mounting Vectashield ${ }^{\circledR}$ mounting media containing 4',6diamidino-2-phenylindole (DAPI) (Vector Laboratories, CA, USA). Confocal microscopy of stained cells was carried out on the Leica TCS SP8 platform (Leica Microsystems, Wetzlar, Germany), equipped with $63 \times$ oil-immersion objective lenses. Within each experiment, image acquisition and processing parameters were kept consistent for each sample. 


\section{Synthesis of $\mathrm{N}_{3}-\mathrm{Bn}$-DTPA}

S-2-(4-Isothiocyanatobenzyl)-diethylenetriamine pentaacetic acid) hydrochloric acid salt (p-SCNBn-DTPA) (50 mg, $0.077 \mathrm{mmol}, 1 \mathrm{eq})$ in DMSO (1 mL) was combined with 3-azido-1propanamine $(8.4 \mathrm{mg}, 0.085 \mathrm{mmol}, 1.1 \mathrm{eq})$ in $\mathrm{MilliQ}{ }^{\circledR} \mathrm{H}_{2} \mathrm{O}(1 \mathrm{~mL})$ and the solution was diluted with MilliQ ${ }^{\circledR} \mathrm{H}_{2} \mathrm{O}(2 \mathrm{~mL})$. To this, aqueous $\mathrm{KOH}$ was added until $\mathrm{pH}$ 8-9. A precipitate was immediately observed which re-dissolved as more $\mathrm{KOH}$ was added. The reaction was left to stir at room temperature and monitored by LRMS. Once the reaction was determined to be complete by LRMS, the DMSO/ $\mathrm{H}_{2} \mathrm{O}$ was removed by a stream of $\mathrm{N}_{2}$ overnight. The crude mixture was dissolved in $\mathrm{CH}_{2} \mathrm{Cl}_{2}(3 \mathrm{~mL})$, resulting in a dense aggregation to form. The $\mathrm{CH}_{2} \mathrm{Cl}_{2}$ was decanted and the aggregate was washed a further two times with $\mathrm{CH}_{2} \mathrm{Cl}_{2}(\sim 5 \mathrm{~mL})$. The residue was dissolved in a minimal amount of MilliQ ${ }^{\circledR} \mathrm{H}_{2} \mathrm{O}(200-500 \mu \mathrm{L})$ and loaded by gravity onto a $\mathrm{RP}-18 \mathrm{SPE}$ cartridge (Sep-Pak C18 plus short cartridge, $360 \mathrm{mg}$ sorbent, Waters ${ }^{\mathrm{TM}}$ ), preconditioned with MeCN $(10 \mathrm{~mL})$ and $\mathrm{H}_{2} \mathrm{O}(40 \mathrm{~mL})$. The product was eluted in small fractions in $\mathrm{H}_{2} \mathrm{O}$. Fractions that contained $\mathrm{N}_{3}$-Bn-DTPA as determined by LCMS were recombined and dried to afford the product as a colourless solid (11.6 mg, 23\%). ${ }^{1} \mathrm{H}$ NMR (400 MHz, $\left.\mathrm{D}_{2} \mathrm{O}\right) \delta 7.34(\mathrm{~d}, J=8.37 \mathrm{~Hz}$, $2 \mathrm{H}, 2 \times \mathrm{ArCH}), 7.24(\mathrm{~d}, J=8.27 \mathrm{~Hz}, 2 \mathrm{H}, 2 \times \mathrm{ArCH}), 3.84-2.47(\mathrm{~m}, 25 \mathrm{H}), 1.95-1.79(\mathrm{~m}, 2 \mathrm{H})$. HRMS $m / z$ (ESI)- Found: 639.22028, $\mathrm{C}_{25} \mathrm{H}_{36} \mathrm{~N}_{8} \mathrm{O}_{10} \mathrm{~S}$ requires [M-H]- 639.22023 ; LRMS m/z $\left(\mathrm{ESI}^{+}\right): 755,717,679\left([\mathrm{M}+\mathrm{K}]^{+}, 100 \%\right) 641\left([\mathrm{M}+\mathrm{H}]^{+}, 90 \%\right)$. HPLC analysis confirmed the product purity was $>95 \%$.

\section{Clonogenic colony formation assay}

Aliquots of $2.5 \times 10^{2}$ cells were plated in 6 well plates with complete culture medium and incubated overnight at $37^{\circ} \mathrm{C}$ with $5 \% \mathrm{CO}_{2}$. Culture medium was removed, and cells washed with PBS before 
addition of fresh culture medium containing either $\left[{ }^{111} \mathrm{In}\right] \mathrm{In}-\mathrm{GFP}-\mathrm{G} 1-\mathrm{TAT}(1.5 \mathrm{nM}, 1 \mathrm{MBq} / \mu \mathrm{g})$, $\left[{ }^{111} \mathrm{In}\right] \mathrm{In}-\mathrm{GFP}-\mathrm{G} 1(1.5 \mathrm{nM}, 1 \mathrm{MBq} / \mu \mathrm{g})$, or no RIC, followed by incubation at $37^{\circ} \mathrm{C}$ for a further 60 min. Supernatant containing unbound radiolabelled compound was removed and cells were washed twice with PBS before addition of fresh culture medium. To allow for colony formation, cells were incubated for a further 14 days without disruption. Cells were then washed with PBS and stained with crystal violet biological stain (Sigma, Dorset, UK) at room temperature for $24 \mathrm{~h}$. Stained cells were washed with $\mathrm{dH}_{2} \mathrm{O}$ and dried before colonies were imaged and counted using the GelCount ${ }^{\mathrm{TM}}$ colony counter (Oxford Optronics, Abingdon, UK).

\section{SPECT/CT imaging}

Tumour xenografts of H1299 WT and H2B-EGFP transfected cells were established on the flanks of 8 -week-old Balb/c nu/nu mice by subcutaneous injection of $2 \times 10^{6}$ cells, suspended in $150 \mu \mathrm{l}$ of equal volume ratio of PBS and Phenol Red Free High Concentration Matrigel (Corning). Tumours were allowed to grow for 4 weeks to achieve a volume of approximately $180 \mathrm{~mm}^{3}$ prior to imaging studies. For each imaging session, anaesthesia was induced and maintained by inhalation of $4 \%$ and $2 \%$ isoflurane respectively in room air supplemented with oxygen $(80 \% / 20 \%$ $\mathrm{v} / \mathrm{v}$; flow rate $1 \mathrm{~L} / \mathrm{min})$. Anaesthesia depth was based on respiration rate monitored using a pneumatic cushion, and isoflurane levels were adjusted to maintain a respiration rate of 40-60 breaths per minute. Induction and recovery were performed in a heated unit with a base temperature of around $37^{\circ} \mathrm{C}$ to maintain a core temperature of $36^{\circ} \mathrm{C}$ (see ref 22). All SPECT/CT imaging was carried out using the VECTor ${ }^{4}$ imaging system (MILabs, Utrecht, Netherlands) with a rat collimator (HE-UHR-RM, $1.8 \mathrm{~mm}$ pinhole). Animals were initially CT imaged (55 kV, 19 $\mathrm{mA})$, immediately followed by list mode SPECT (0-1200 keV) using MILabs acquisition software 
v11.0. Triple energy window-based scatter correction was applied for each photon peak window ( ${ }^{111} \mathrm{In}: 155.7-190.3 \mathrm{keV}$ and $218.7-267.3 \mathrm{keV}$ with background windows set to $148.8-155.7 \mathrm{keV}$, 190.3-197.2 keV, 209.0-218.7 keV, and 267.3-277.0 keV) with a background weight and calibration factor of 2.5 and 1 respectively. All images were reconstructed with MILabs reconstruction software v11.0 on $0.6-\mathrm{mm}$ isotropic 3D voxel grids using similarity regulated ordered-subset expectation maximization (SROSEM). After reconstruction, the SPECT, and their corresponding CT data were coregistered and resampled to equivalent $200-\mu \mathrm{m}$ voxel sizes. CTbased attenuation correction was applied. Reconstructed images were viewed and analysed using PMOD v.3.37 (PMOD Technologies, Zurich, Switzerland). For accurate scaling and quantification of SPECT image data, phantoms were used to determine a calibration factor applied to all images. Image processing and volume of interest (VOI) analysis was carried out using the PMOD software package (version 3.708, PMOD Technologies, Zürich, Switzerland). 


\section{Supplemental Figures}

B
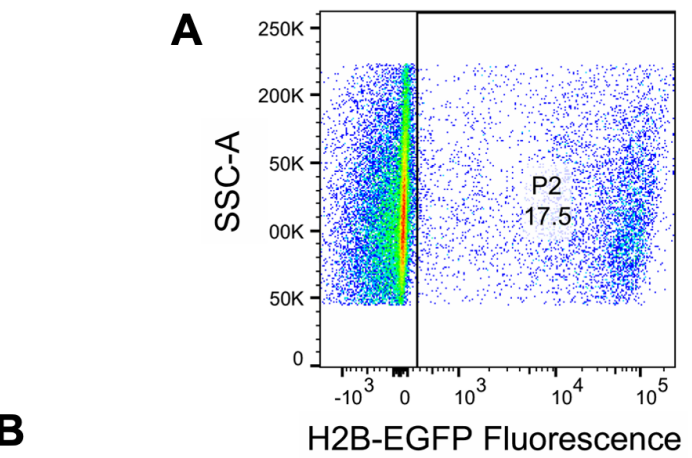
H2B-EGFP 45

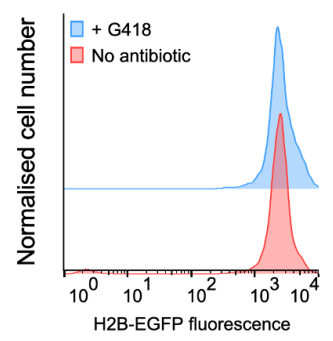

H2B-EGFP 56

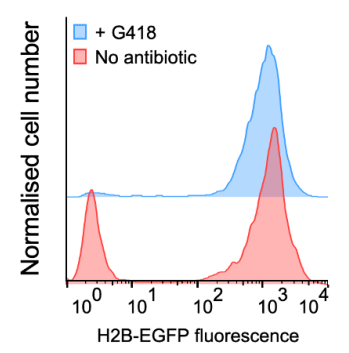

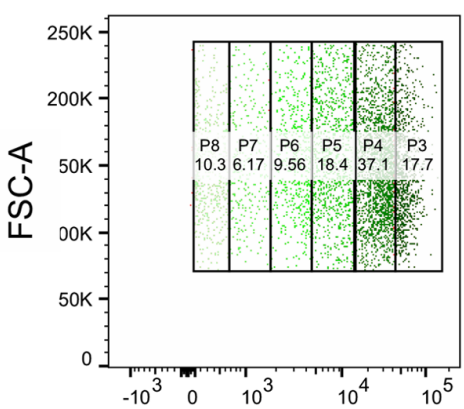

H2B-EGFP Fluorescence

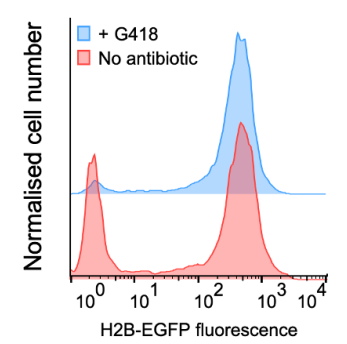

\section{H2B-EGFP 62}

H

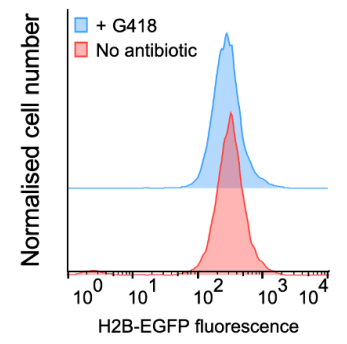

\section{Supplemental Figure 1. Flow assisted cell sorting and stability testing of H2B-EGFP}

transfected cell lines. A) Scatter plot showing initial sorting of heterogenous mixture of H2BEGFP transfected cells by expression level, prior to clonal plating and antibiotic selection. B) Flow cytometry shows changes of H2B-EGFP expression across transfected cell lines after 42 days with and without antibiotic selection $(50 \mu \mathrm{g} / \mathrm{ml} \mathrm{G} 418)$. 

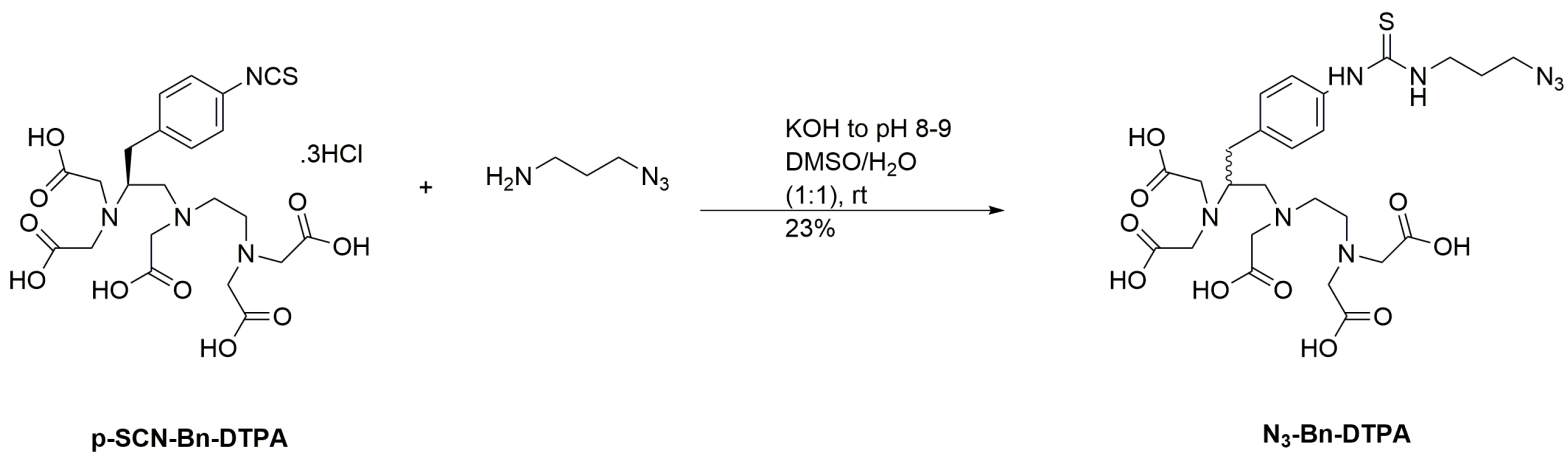

Supplemental Figure 2. Synthesis of N3-Bn-DTPA. Schematic diagram showing the synthesis of $\mathrm{N}_{3}-\mathrm{Bn}-\mathrm{DTPA}$. 


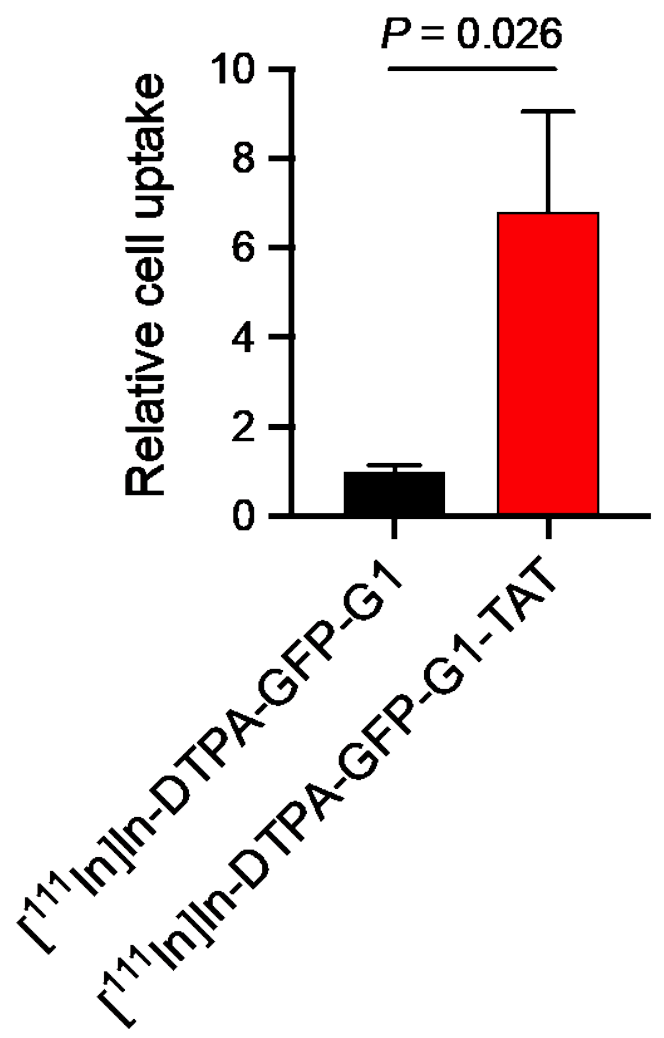

Supplemental Figure 3. Comparison of uptake of [111 In]In-GFP-G1 with and without TAT. In vitro radio-internalisation assays with high H2B-EGFP expressing cell line H2B-EGFP 45 show a significant increase in [ [ $\left.{ }^{11} \mathrm{In}\right] \mathrm{In}-\mathrm{GFP}-\mathrm{G} 1-\mathrm{TAT}$ internalisation in comparison to $\left[{ }^{111} \mathrm{In}\right] \mathrm{In}-\mathrm{GFP}-\mathrm{G} 1$ without TAT. 


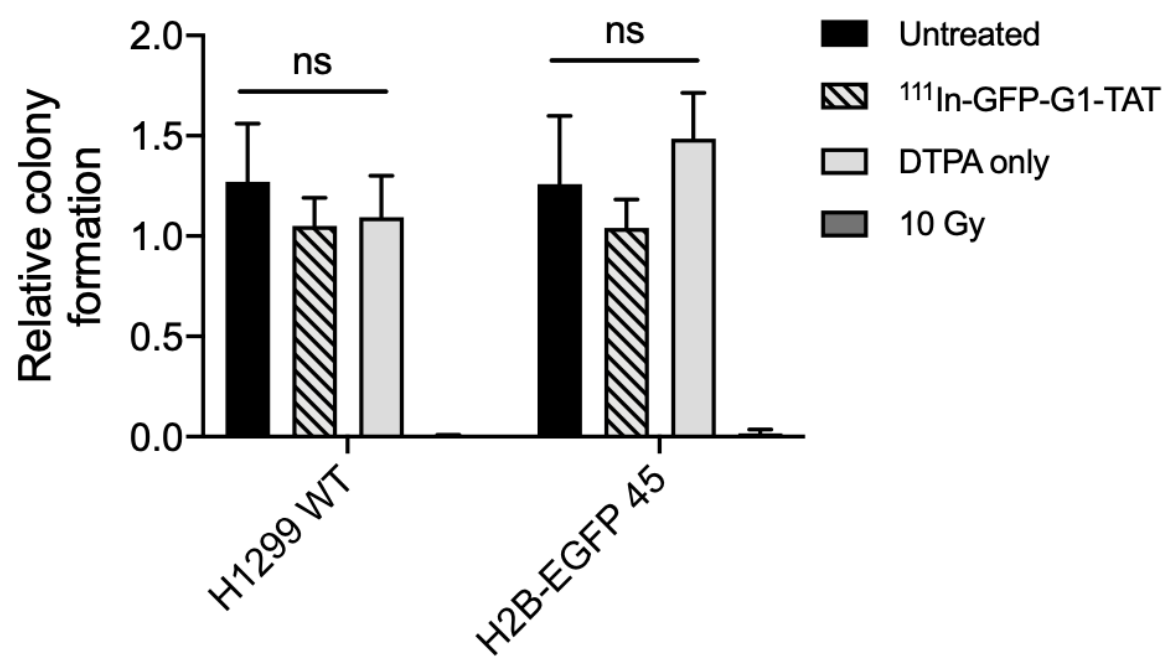

Supplemental Figure 4. Effect of [111 In]In-GFP-G1-TAT uptake on cell viability . In vitro colony formation assay demonstrated no significant difference in relative colony formation between cells exposed to [ $\left.{ }^{111} \mathrm{In}\right]$ In-GFP-G1-TAT, $\left[{ }^{111} \mathrm{In}\right] \mathrm{In}-\mathrm{GFP}-\mathrm{G} 1$ without TAT, and a nontreated control group. 